\title{
The Heat of Formation of Boron Carbide ${ }^{1}$
}

\author{
E. S. Domalski and G. T. Armstrong
}

Institute for Basic Standards, National Bureau of Standards, Washington, D.C. 20234

(October 28, 1967)

\begin{abstract}
The standard heat of combustion in fluorine of a boron carbide sample having the composition $\mathrm{B}_{4.222} \mathrm{C}$ was determined from the heats of combustion of polytetrafluoroethylene and of boron carbidepolytetrafluoroethylene mixtures. The energy of the combustion reaction was measured in an isothermal-jacket bomb calorimeter. From the experimental data, we calculate $-17.1 \mathrm{kcal} \mathrm{mol}^{-1}$ for the heat of formation of boron carbide. By combining all probable errors, we estimate our overall experimental uncertainty to be $2.7 \mathrm{kcal} \mathrm{mol}^{-1}$. The value for the heat of formation of boron carbide is for the phase represented by the formula $B_{4.222} \mathrm{C}$.
\end{abstract}

Key Words: Bomb calorimeter, boron carbide, boron trifluoride, carbon tetrafluoride, heat of combustion, heat of formation, polytetrafluoroethylene.

\section{Introduction}

The determination of the heat of combustion of boron carbide in oxygen by Smith, Dworkin and van Artsdalen [1] ${ }^{2}$ appears to be the only previous work reliable enough to use in deriving a value for the heat of formation of $\mathrm{B}_{4} \mathrm{C}$. Using bomb calorimetric techniques, these authors carried out reaction (1).

$$
\mathrm{B}_{4} \mathrm{C}(\mathrm{c})+4 \mathrm{O}_{2}(\mathrm{~g})=2 \mathrm{~B}_{2} \mathrm{O}_{3} \text { (amorphous) }+\mathrm{CO}_{2}(\mathrm{~g})
$$

They obtained $-683.8 \pm 2.2 \mathrm{kcal} \mathrm{mol}^{-1}$ for the heat of combustion. Using amorphous boron as a reference state and taking $-301.75 \mathrm{kcal} \mathrm{mol}^{-1}$ for the heat of formation of amorphous $\mathrm{B}_{2} \mathrm{O}_{3}{ }^{3}$ they calculated for $\Delta H_{f 298}^{\circ}\left[\mathrm{B}_{4} \mathrm{C}(\mathrm{c})\right],-13.8 \pm 2.7 \mathrm{kcal} \mathrm{mol}{ }^{-1}$. The degree of completeness of combustion was not large, ranging from 21 to 41 percent $\mathrm{B}_{4} \mathrm{C}$ burned. They found that when the amounts of $\mathrm{B}_{2} \mathrm{O}_{3}$ and $\mathrm{CO}_{2}$ produced in the combustion were measured, a deficiency in the carbon dioxide was observed. The authors assumed that some of the carbon in their boron carbide sample failed to burn and remained behind as free carbon.

More recently several authors have referred the heat of formation to crystalline boron. Several different values for $\Delta H_{f 298}^{\circ}\left[\mathrm{B}_{4} \mathrm{C}(\mathrm{c})\right]$ have been suggested, based on the combustion data of Smith, Dworkin, and van Artsdalen, but differing in the values attributed to the heats of transition of amorphous to crystalline boron, and the heat of formation of amorphous $\mathrm{B}_{2} \mathrm{O}_{3}$.

1 This research was sponsored by the Air Force Aero Propulsion Laboratory, Research and Development Division, Air Force Systems Command, Wright-Patterson Air Force Base, Ohio, under USAF Delivery Order No. 33(615)64-1003, and by the Air Force Office of Scientific Research under Order No. OAR ISSA 65-8.

${ }^{2}$ Figures in brackets indicate literature references at the end of this paper.

${ }_{3} \Delta H^{\circ}{ }_{0,4}\left[\mathrm{~B}_{2} \mathrm{O}_{3}(\mathrm{am}) \mid=-301.75 \mathrm{kcal} \mathrm{mol}^{-1}\right.$ was a preliminary value, and in a later publica. tion $[2]$ was changed to $-301.78 \mathrm{kcal} \mathrm{mol}^{-1}$.
The value $-12.2 \mathrm{kcal} \mathrm{mol}^{-1}$, which was for a time widely used, is based on $\Delta H_{f 298}^{\circ}[\mathrm{B}(\mathrm{am})]=0.4 \mathrm{kcal}$ $\mathrm{mol}^{-1}$, and the same value for $\Delta H_{f 298}^{\circ}\left[\mathrm{B}_{2} \mathrm{O}_{3}(\mathrm{am})\right]$ as was used by Smith, Dworkin, and van Artsdalen.

The JANAF Thermochemical Tables $[3 \mid$ give -9.3 kcal mol-1 for the heat of formation of $\mathrm{B}_{4} \mathrm{C}$ using the same combustion data, and other appropriately chosen data from within the JANAF compilation to perform the calculation. Other values have been reported for the heat of formation of $\mathrm{B}_{4} \mathrm{C}$ [4-8], but because of their obscurity of source or lack of experimental detail, they cannot be readily discussed here.

We have undertaken the measurement of the heat of combustion of $\mathrm{B}_{4} \mathrm{C}$ in fluorine as a route to the determination of its heat of formation. Due to the lack of completeness of combustion in the work of Smith, Dworkin, and van Artsdalen [1], and certain assumptions made in their treatment of the experimental data, we felt a redetermination by another method was warranted. Combustion in fluorine offers the distinct advantage of giving gases for all major reaction products. In addition, a procedure was available for the combustion of refractory compounds which had given a large degree of completeness of combustion for several substances [9].

\section{Materials}

The sample of boron carbide was obtained from the Carborundum Company as a fine powder having a maximum particle size of $75 \mu$. The sample was analyzed and the results are shown in table 1 . The analyses for boron, carbon, and metallic impurities were performed using appropriate wet chemical and instrumental methods. The nitrogen content was 
TABLE 1. Analysis of boron carbide (percent by weight)

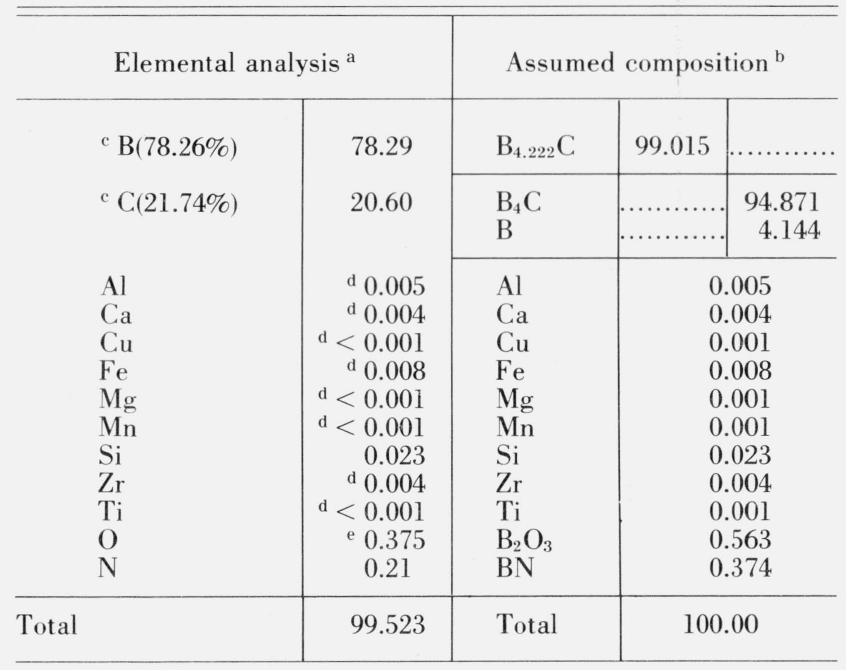

a Unless otherwise stated the elemental analyses were performed by the NBS Analysis and Purification Section.

b The assumed composition was obtained from the elemental analysis after the latter was normalized.

c Theoretical for $\mathrm{B}_{4} \mathrm{C}$.

d Analysis by the supplier.

e Analysis by Ledoux \& Company.

determined by the Kjeldahl method and the oxygen analysis was made by the inert-gas fusion method.

Preliminary analyses of the sample at NBS for boron and carbon showed not only poor agreement among individual determinations but also poor agreement with the analysis provided by the supplier. After a thorough study was made of the past analytical work performed on the sample, a final analysis for boron and carbon was obtained by the NBS Analysis and Purification Section, and appears in the second column of table 1 . Three determinations of the boron content had an average deviation of 0.06 percent, and five determinations of carbon had an average deviation of 0.03 percent.

The total elemental analysis of 99.523 was normalized and we assumed the metallic impurities to be present as the elements. The oxygen and nitrogen were assumed to be present as $\mathrm{B}_{2} \mathrm{O}_{3}$ and $\mathrm{BN}$, respectively. Calculation of the boron to carbon ratio shows the stoichiometry to be $\mathrm{B}_{4.222} \mathrm{C}$, slightly below carbonsaturated boron carbide. Interpretation of the actual boron carbide phase present will be discussed in Section 8.2 .

The $\mathrm{B}_{4} \mathrm{C}$ sample was examined using x-ray techniques by the NBS Crystallography Section and was found to have the following hexagonal lattice constants: $a=5.599 \AA$ and $c=12.08 \AA$; in good agreement with existing data $(a=5.60 \AA$ and $c=12.12 \AA[10])$. Examination of the $\mathrm{x}$-ray pattern at NBS and at another laboratory ${ }^{4}$ revealed no lines attributable to graphite or crystalline boron. Samples of boron carbide that are boron rich show significantly larger lattice constants

${ }^{4}$ We thank P. W. Gilles, University of Kansas, Lawrence, Kansas, for his assistance in the $\mathrm{x}$-ray examination of our sample for graphite (Aug. 1966).
[11] than those observed for our sample, indicating the stoichiometry of our sample to be very close to carbon-saturated boron carbide.

The polytetrafluoroethylene powder ("Teflon 7") and polytetrafluoroethylene film (FEP Fluorocarbon film, type A) used in preparing mixtures for the combustion measurements were described in an earlier publication [12]. Neither the polytetrafluoroethylene powder nor film was modified or treated in any special way prior to use. The energy of combustion, $\Delta E_{303}^{\circ}$, of the polytetrafluoroethylene film and powder was $-10,372.8 \pm 3.1 \mathrm{~J} \mathrm{~g}^{-1}$. The uncertainty cited was the overall experimental error. The fluorine used in the heat measurements was found to be 99.40 percent $F_{2}$. The analysis was performed by absorbing the fluorine in mercury and observing the pressure of the residual gases [13]. The composition of the residue was determined by examination in a mass spectrometer as previously reported [14].

\section{Preparation of Sample Pellets}

Attempts to prepare suitable pellets of boron carbide for a combustion measurement without the aid of an auxiliary material were not successful because of the extreme hardness of $\mathrm{B}_{4} \mathrm{C}$. A composite, capable of being pelleted, was obtained by adding polytetrafluoroethylene powder to boron carbide powder which had been introduced into a thermosealable polytetrafluoroethylene bag. The powders were mixed until reasonable homogeneity had been obtained and the bagged mixture was pressed into pellet form. An additional coating of polytetrafluoroethylene was provided around the pellet as a precaution to preclude the possible reaction with fluorine in the combusion bomb prior to the time of ignition. The preparative procedures have been described in detail (methods A and $\mathrm{B}$ ) in an earlier paper [12].

Much care is needed in keeping track of the cumulative mass of the sample as the polytetrafluoroethylene and boron carbide powders are added because some losses are always observed and their distribution affects the results of the experiment significantly. Average masses for the components of a coated pellet were as follows: polytetrafluoroethylene bag, $0.3 \mathrm{~g}$; polytetrafluoroethylene powder, $1.90 \mathrm{~g} ; \mathrm{B}_{4} \mathrm{C}$ powder, $0.18 \mathrm{~g}$; polytetrafluoroethylene coating, $0.7 \mathrm{~g}$; loss of polytetrafluoroethylene in sealing the bag, $0.21 \mathrm{mg}$; loss of mixture in pelleting, $0.20 \mathrm{mg}$.

The densities used for the polytetrafluoroethylene film, polytetrafluoroethylene powder, and $\mathrm{B}_{4} \mathrm{C}$ in making buoyancy corrections were $2.15,2.16$, and 2.52 $\mathrm{g} \mathrm{cm}^{-3}$ [15], respectively. Weighings of pelleted mixtures and intermediate stages were made to $0.01 \mathrm{mg}$.

\section{Calorimetric System}

No major changes had been made in the bomb calorimeter, thermometric system or combustion bomb since our earlier work [12] which was carried out with the same apparatus. The apparatus will be discussed here only briefly. 
An isothermal-jacket, stirred-water calorimeter was used for these measurements. The jacket was maintained at a constant temperature near $30{ }^{\circ} \mathrm{C}$ to within $0.002{ }^{\circ} \mathrm{C}$. Temperature changes in the calorimeter were measured to $0.0001{ }^{\circ} \mathrm{C}$ with a G-2 Mueller bridge in conjunction with a platinum-resistance thermometer. Reactions were carried out in an "A" nickel combustion bomb (volume, $360 \mathrm{~cm}^{3}$ ), designed for service with fluorine. Two aluminum electrodes each suspended from the bomb head by a monel rod held a tungsten fuse $(0.002$ in diam) which contributed about $20 \mathrm{~J}$ to the combustion energy, assuming complete combustion. The electrical energy for ignition of the fuse was assumed to be negligible. The quantities of boron carbide and polytetrafluoroethylene in the pellets were adjusted to produce a temperature rise in the calorimeter of about three degrees (27 to $30{ }^{\circ} \mathrm{C}$ ). For procedures dealing with the loading and emptying of the combustion bomb, and for details of the design and construction of the fluorine manifold, our earlier work should be consulted [16].

\section{Products of Combustion}

Our previous work $[12,16]$ has established that polytetrafluoroethylene burns in 15 to 21 atm of fluorine to carbon tetrafluoride as the only major product. Higher fluorocarbons were not detected in amounts greater than 0.02 mole percent. The product gases from representative experiments were analyzed in a mass spectrometer after absorption of the excess fluorine in mercury.

The mass spectrometric examination of product gases from the combustion of a pelleted mixture of boron carbide and polytetrafluoroethylene showed no sign of boron trifluoride. This was similar to the results observed when product gases from the combustion of a pelleted mixture of boron and polytetrafluoroethylene were examined. In both cases, we suspect that under the conditions of the reaction of fluorine with mercury, an interaction of some kind takes place between $\mathrm{BF}_{3}$ and the mercury fluoride formed during the absorption of fluorine. In other respects the mass spectra appeared comparable to those observed showing carbon tetrafluoride to be the only major product when only polytetrafluoroethylene is burned in fluorine.

Boron trifluoride was identified as a combustion product by infrared spectrometry. Examination in the region 400 to $650 \mathrm{~cm}^{-1}$ of a sample of the bomb product gases containing excess fluorine revealed the $\mathrm{BF}_{3}$ band at $481 \mathrm{~cm}^{-1}$ and the $\mathrm{CF}_{4}$ band at $630 \mathrm{~cm}^{-1}$. Spectra of the evacuated cell and of $\mathrm{BF}_{3}$ alone were taken over the region mentioned above to substantiate the identification. The cell used was $8 \mathrm{~cm}$ long and had polyethylene windows 0.0625 in thick.

\section{Calibration Experiments}

Twenty calibration experiments were performed in which benzoic acid (Standard Sample 39i) was burned in $30 \mathrm{~atm}$ of oxygen and with one $\mathrm{cm}^{3}$ of distilled water in the nickel combustion bomb. Their consistency and reproducibility have been discussed in our earlier paper [12]. The average energy equivalent was calculated to be $14,803.27 \pm 2.07 \mathrm{~J} \mathrm{deg}^{-1}$. The uncertainty cited was obtained by multiplying the standard deviation of the mean by the appropriate factor in the Student $t$ distribution at the 95 percent confidence level. The energy equivalent is that of the standard initial oxygen-combustion calorimeter which included the nickel combustion bomb with $30 \mathrm{~atm}$ of oxygen, a platinum crucible and fuse support wires, platinum fuse ( $2 \mathrm{~cm}$ long, $0.01 \mathrm{~cm}$ diam), a stainless-steel (type 304) liner, $1 \mathrm{~cm}^{3}$ of distilled water, monel pellet holder, and no sample. Fastened to the bomb were a heater and ignition leads. The mass of the calorimeter vessel and water was $3750.0 \mathrm{~g}$. The calorimetric data obtained in the calibration experiments were programmed for the IBM 7094 computer according to the procedure outlined by Shomate [17].

With the appropriate heat capacity data, the energy equivalent of the standard oxygen-combustion calorimeter was adjusted to the proper value for the fluorine experiments. This involved allowing for the heat capacities of $30 \mathrm{~atm}$ of oxygen, $1 \mathrm{~cm}^{3}$ of distilled water, the platinum ware, 21 atm of fluorine, and two aluminum electrodes. The application of these corrections gave $14,805.17 \mathrm{~J} \mathrm{deg}^{-1}$ for the energy equivalent of the standard initial fluorine combustion calorimeter for the temperature range used $\left(27\right.$ to $\left.30^{\circ} \mathrm{C}\right)$.

\section{Fluorine Combustion Experiments}

Eight calorimetric measurements were made in which pellets of boron carbide and polytetrafluoroethylene were burned in 21 atm of fluorine. These measurements are summarized in table 2. In each experiment the sample pellet was placed in the recess of an "A" nickel plate on the bottom of the bomb. The bomb was attached to the fluorine manifold and filled to 21 atm with fluorine by the usual procedure. All bomb parts (bomb base, bomb-head assembly, electrodes, liner and nickel plate) were weighed before the first experiment and after each successive experiment. The bomb parts were washed with water and dried before the weighings were made.

The calorimetric data also included seven experiments, which have been previously reported in detail [12], in which polytetrafluoroethylene was burned in $21 \mathrm{~atm}$ of fluorine. The value listed in section 2 for the energy of combustion, $\Delta E_{303}^{\circ}$, was determined in these experiments.

The numbered entries in table 2 are as follows: (1a) mass of the boron carbide sample in the pellet, corrected for weight loss in preparation and for recovery of unburned sample.

(1b) mass of polytetrafluoroethylene in the pellet, corrected for weight loss.

(2) pressure of fluorine introduced into the bomb prior to combustion, corrected to $30^{\circ} \mathrm{C}$.

(3) energy equivalent of the calorimeter for a given experiment.

(4) temperature change of the calorimeter thermom- 
TABLE 2. Boron carbide-"Teflon 7'” combustion experiments

\begin{tabular}{|c|c|c|c|c|c|c|c|c|}
\hline Experiment No. & 1 & 2 & 3 & 4 & 5 & 6 & 7 & 8 \\
\hline 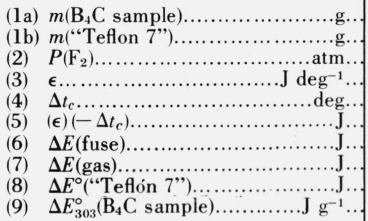 & $\begin{array}{c}0.201948 \\
2.775820 \\
21.5 \\
14,800.14 \\
3.27109 \\
-48,412.6 \\
18.5 \\
13.1 \\
28,793.0 \\
-96,995.3\end{array}$ & $\begin{array}{c}0.184980 \\
2.738097 \\
21.7 \\
14,804.85 \\
3.13267 \\
-46,378.7 \\
17.4 \\
12.9 \\
28,401.7 \\
-97,019.7\end{array}$ & $\begin{array}{c}0.178836 \\
2.776954 \\
22.1 \\
14,804.13 \\
3.11938 \\
-46,179.7 \\
18.6 \\
13.3 \\
28,804.8 \\
-96,977.1\end{array}$ & \begin{tabular}{|c|}
0.179005 \\
2.709381 \\
21.3 \\
$14,799.56$ \\
3.07716 \\
$-45,540.6$ \\
17.5 \\
12.5 \\
$28,103.9$ \\
$-97,241.4$
\end{tabular} & \begin{tabular}{|c|}
0.182011 \\
3.028289 \\
21.4 \\
$14,805.42$ \\
3.31773 \\
$-49,120.4$ \\
20.3 \\
13.9 \\
$31,411.8$ \\
$-97,106.2$
\end{tabular} & $\begin{array}{c}0.172072 \\
2.895316 \\
22.3 \\
14,800.13 \\
3.16025 \\
-46,772.1 \\
20.4 \\
14.0 \\
30,032.5 \\
-97,082.6\end{array}$ & $\begin{array}{c}0.178745 \\
2.806986 \\
21.1 \\
14,804.42 \\
3.14252 \\
-46,523.2 \\
20.4 \\
12.9 \\
29,116.3 \\
-97,197.7\end{array}$ & $\begin{array}{c}0.168138 \\
3.123387 \\
21.3 \\
14,804.25 \\
3.29554 \\
-48,788.0 \\
18.8 \\
14.5 \\
32,398.3 \\
-97,279.6\end{array}$ \\
\hline
\end{tabular}

(10) $\Delta E_{303}^{\circ}\left(\mathrm{B}_{4} \mathrm{C}\right.$ sample $)=-97,112.5 \mathrm{~J} \mathrm{~g}^{-1}$

(11) Std. dev. mean $=40.8 \mathrm{~J} \mathrm{~g}^{-1}=0.5 \mathrm{kcal} \mathrm{mol}^{-1}$

(12) $\Delta E_{298}^{\circ}-\Delta E_{303}^{\circ}=1.1 \mathrm{~J} \mathrm{~g}^{-1}$

(13) $\Delta E_{298}^{\circ}\left(\mathrm{B}_{4} \mathrm{C}\right.$ sample $)=-97,111.4 \mathrm{~J} \mathrm{~g}^{-}$

eter, corrected for heat of stirring and heat transfer. (5) total energy change in the bomb process.

(6) energy liberated by the tungsten fuse assuming the fuse burns according to the reaction:

$$
\mathrm{W}(\mathrm{c})+3 \mathrm{~F}_{2}(\mathrm{~g})=\mathrm{WF}_{6}(\mathrm{~g}) \text {. }
$$

From the heat of formation of $\mathrm{WF}_{6}$ [18], we calculate 9.44 $\mathrm{J} \mathrm{mg}^{-1}$ for the energy of combustion of the fuse. (7) net energy correction for the hypothetical compression and decompression of bomb gases.

$$
\left.\left.\Delta E(\text { gas })=\Delta E^{i}(\text { gas })\right]_{0}^{P_{i(\text { gas })}}+\Delta E^{f}(\text { gas })\right]_{P_{f(\text { gas })}}^{0}
$$

(8) standard energy of combustion of polytetrafluoroethylene per gram at $30^{\circ} \mathrm{C}$ multiplied by the corrected mass of polytetrafluoroethylene in the pellet.

(9) standard energy of combustion of the sample, per gram.

(10) average standard energy of combustion of the sample, per gram.

(11) standard deviation of the mean of the average cited in (10).

(12) correction based on heat capacities, converting the reference temperature to $298{ }^{\circ} \mathrm{K}$.

(13) standard energy of combustion at $298{ }^{\circ} \mathrm{K}$, not corrected for impurities.

The heat capacities at constant pressure, $C_{p}$, used in the calculation of entries (3) and (12) are as follows in cal $\mathrm{deg}^{-1} \mathrm{~g}^{-1}$ at $298{ }^{\circ} \mathrm{K}$; boron carbide, 0.23 [3]; and polytetrafluoroethylene, 0.28 [19]. The heat capacities at constant volume, $C_{v}$, used in the calculation of entries (3) and (12) were $5.52[20], 12.62[21]$, and 10.04 [22] cal deg-1 $\mathrm{mol}^{-1}$, respectively, for fluorine, carbon tetrafluoride, and boron trifluoride at $303{ }^{\circ} \mathrm{K}$.

Washburn corrections, entry (7) were calculated following the procedure outlined by Hubbard [23] for experiments in which fluorine is used as the oxidant. The coefficients $\left[\partial E /\left.\partial P\right|_{T}=-T[d B / d T]\right.$ were found in tables (based on a Lennard-Jones 6-12 potential function) as compiled by Hirschfelder, Curtiss, and Bird [24] using the appropriate force constants. The force constants used for fluorine, carbon tetrafluoride, and boron trifluoride were those determined by White, $\mathrm{Hu}$, and Johnston [25], Douslin [26], and Brooks and Raw [27], respectively. Force constants appropriate to the mixtures of $\mathrm{F}_{2}, \mathrm{CF}_{4}$ and $\mathrm{BF}_{3}$ in the reaction products were calculated from those for the pure components.

In calculating the corrections for the combustion of other impurities in the boron carbide sample (see Section 8.2) the following values for the heats of formation of various substances were used, and are given in kcal mol-1: $\mathrm{B}_{2} \mathrm{O}_{3},-304.20$ [28]; $\mathrm{BN},-60.8$ [28]; $\mathrm{AlF}_{3},-361.0$ [12, 16]; $\mathrm{CaF}_{2},-290.3$ [29]; $\mathrm{CuF}_{2},-126.9$ [29]; $\mathrm{FeF}_{3},-235$ [30]; $\mathrm{MgF}_{2},-268.7$ [31]; $\mathrm{MnF}_{3},-238$ [30]; $\mathrm{SiF}_{4},-385.98$ [32]; $\mathrm{ZrF}_{4},-456.80$ [33]; $\mathrm{TiF}_{4}$, $-394.19[34]$.

The combustion experiments were programmed for machine calculation in the same way as the calibration experiments. However, the only valid data calculated by the computer were the corrected temperature rises, $\Delta t_{c}$, because the program had not been modified to accommodate the use of fluorine as the oxidant.

Atomic weights were taken from the 1961 table of atomic weights, based on ${ }^{12} \mathrm{C}=12$, adopted by the International Union of Pure and Applied Chemistry [35]. The unit of energy is the joule and we use the calorie defined as $4.1840 \mathrm{~J}$.

\section{Discussion and Results}

\subsection{Analysis of Combustion Residues}

A residue amounting to less than one $\mathrm{mg}$, which was assumed to be unburned polytetrafluoroethylene and/or carbon, was observed in experiments involving polytetrafluoroethylene alone. No correction was applied to any experiment for this residue, and we assumed that the formation of the residue took place in all experiments approximately in proportion to the amount of polytetrafluoroethylene initially present. The heat of combustion per gram of polytetrafluoroethylene would be constant and the error due to residue formation would be eliminated when the energy due to the combustion of polytetrafluoroethylene in the pelleted mixture was subtracted from the total energy released in the combustion.

After a combustion experiment on pelleted mixtures of boron carbide and polytetrafluoroethylene, a residue was found on the nickel support plate. The mass of the residue was determined by weighing the plate 
before and after an experiment. The average mass found from these weighings was $1.0 \mathrm{mg}$, of which 0.13 to $0.19 \mathrm{mg}$ was estimated to be boron carbide on the basis of the amount of boron found in it. The manner in which the residue was gathered from the nickel plate and analyzed for boron was the same as with the boron-polytetrafluoroethylene combustion residues [14]. Analyses of known masses of boron carbide by this method showed good reproducibility and no bias in the determination of boron. Observations made on the nickel plate after combustion residues had been gathered showed small globules of melted tungsten adhering to the plates. We estimate this mass contribution from the spattering of molten tungsten from ignition of the fuse to be $0.8 \mathrm{mg}$ per experiment [12]. Other effects likely to contribute to the composition of the combustion residue are hygroscopicity of the residue and reaction of the nickel plate with fluorine. However, these effects are presumably small and slow, and no corrections have been made for them.

A non-calorimetric combustion of a pelleted mixture of boron carbide and polytetrafluoroethylene was performed after which the residue was analyzed for its carbon content. The amount found was $0.08 \mathrm{mg}$, which is comparable to the amount of carbon found in a residue when only polytetrafluoroethylene is burned in fluorine [12].

\subsection{The Heat of Formation of Boron Carbide}

The calculation of the heat of formation of boron carbide is shown in detail in table 3 . Two calculations are given. In one we assume that the boron carbide

TABLE 3. Calculation of the heat of formation of boron carbide

\begin{tabular}{|c|c|c|}
\hline 1. stoichiometry of boron carbide....... & $\mathrm{B}_{4.222} \mathrm{C}$ & $\mathrm{B}_{4} \mathrm{C}$ \\
\hline 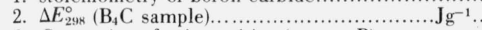 & $-97,111.4$ & $-97,111.4$ \\
\hline 3. Corrections for impurities (except B).. & 234.2 & 234.2 \\
\hline 4. Correction for excess boron....................... & & $4,342.0$ \\
\hline 5. Fraction of sample present as boron carbide.... & 0.99015 & 0.9487 \\
\hline 6. $\Delta E_{298}^{\circ}$ (Reaction 2), J (g, boron carbide $)^{-1} \ldots \ldots$ & $-97,840.9$ & $-97,537.9$ \\
\hline 7. $\Delta n R T, \mathrm{~J}(\mathrm{~g} \text {, boron carbide })^{-1} \ldots \ldots \ldots \ldots \ldots \ldots$ & -133.8 & 134.6 \\
\hline 8. $\Delta H_{298}^{\circ}($ Reaction 2$), \mathrm{J}$ (g, boron carbide $)^{-1} \ldots \ldots \ldots$ & $-97,974.7$ & $-97,672.5$ \\
\hline 9. $\Delta H_{298}^{\circ}($ Reaction 2)....................... & $-1,350.1$ & $-1,289.9$ \\
\hline 10. $\Delta H_{f 298}^{\circ}$ (boron carbide), (Reaction 3 )... kcal mol-1. & -17.1 & -17.1 \\
\hline 11. $\Delta H_{f 298}^{\circ}$ (combustion products). & $-1,367.2$ & $-1,307.0$ \\
\hline
\end{tabular}

phase is non-stoichiometric as implied by the chemical analysis $\left(B_{4.222} \mathrm{C}\right)$. In the other we assume that the sample is stoichiometric $\mathrm{B}_{4} \mathrm{C}$ with an excess of elemental boron, sufficient to make the total boron to carbon ratio 4.222 . The datum in row 2 of table 3 is the uncorrected energy of combustion of the boron carbide sample taken from table 2, entry (13). The corrected energy of combustion of boron carbide of the assigned stoichiometry (row 6) is obtained by subtracting the corrections for the impurities and excess boron (rows 3 and 4) from row 2, and dividing the remainder by the fraction of the sample present as boron carbide (row 5). Addition of the $\triangle n R T$ term (row 7) to the corrected energy of combustion gives the heat of combustion (row 8). The combustion processes for the two limiting stoichiometries assigned are given by reactions $(2 \mathrm{a})$ and $(2 \mathrm{~b})$.

$$
\begin{aligned}
\mathrm{B}_{4.222} \mathrm{C}(\mathrm{c})+8.333 \mathrm{~F}_{2}(\mathrm{~g}) & =4.222 \mathrm{BF}_{3}(\mathrm{~g})+\mathrm{CF}_{4}(\mathrm{~g}) \\
\mathrm{B}_{4} \mathrm{C}(\mathrm{c})+8 \mathrm{~F}_{2}(\mathrm{~g}) & =4 \mathrm{BF}_{3}(\mathrm{~g})+\mathrm{CF}_{4}(\mathrm{~g}) \\
4.222 \mathrm{~B}(\mathrm{c})+\mathrm{C}(\mathrm{c}, \text { graphite }) & =\mathrm{B}_{4.222} \mathrm{C}(\mathrm{c}) \\
4 \mathrm{~B}(\mathrm{c})+\mathrm{C}(\mathrm{c}, \text { graphite }) & =\mathrm{B}_{4} \mathrm{C}(\mathrm{c})
\end{aligned}
$$

The data presented in row 9 are equivalent to that in row 8 except the units are $\mathrm{kcal}^{\mathrm{mol}}{ }^{-1}$ instead of $\mathrm{J} \mathrm{g}^{-1}$. With the aid of our previously determined values for the heats of formation of carbon tetrafluoride, -222.87 kcal $\mathrm{mol}^{-1}[12]$ and boron trifluoride, $-271.03 \mathrm{kcal}$ $\mathrm{mol}^{-1}$ [14], the sum of the heats of formation of the products (row 11) is calculated. The heat of formation of boron carbide (row 10) is obtained as the difference between the sum of the heats of formation of the combustion products (row 11) and the heat of combustion (row 9). The two calculations, referring respectively to reactions (3a) and (3b) give exactly the same result for the heat of formation of boron carbide, $-17.1 \mathrm{kcal}$ $\mathrm{mol}^{-1}$, and do not indicate a preferred representation. The identity of the results of the two methods of calculation is due to the fact that excess free elemental boron has a zero heat of formation. This duality in the calculation could be extended to any data on the heats of formation of nonstoichiometric binary compounds in which there is ambiguity with respect to the nature of the nonstoichiometry.

The absence of any lines in the x-ray spectrum of our sample attributable to crystalline boron causes us to reject the calculation involving free elemental boron, and to favor the nonstoichiometric formula, $\mathrm{B}_{4.222} \mathrm{C}$, as representative of the heat measurements. A quantity as large as 4.144 percent free crystalline boron in the boron carbide sample should have been observed in the $\mathrm{x}$-ray spectrum even though this value is close to the limit of detectability of the method (1 to 3 percent). No definitive remarks are possible regarding the presence of amorphous boron in our sample from the x-ray examination. We have assumed the amorphous phase to be absent in the treatment of the data.

\subsection{Sources of Error}

Over 90 percent of the impurity correction in table 3 , row 3 depends on the oxygen and nitrogen analyses. If both these analyses are in error by absolute amounts of 0.1 percent, a corresponding error of $0.8 \mathrm{kcal} \mathrm{mol}-1$ in the heat of formation of boron carbide is possible.

From our chemical analyses of total boron and total carbon, we calculate the average error in the $\mathrm{B} / \mathrm{C}$ ratio to be 0.1 percent which would contribute an error of $1.0 \mathrm{kcal} \mathrm{mol} \mathrm{m}^{-1}$ in the heat of formation.

The error introduced by the uncertainties in the heats of formation of $\mathrm{BF}_{3}(\mathrm{~g}), 0.51 \mathrm{kcal} \mathrm{mol}-1$, and $\mathrm{CF}_{4}(\mathrm{~g}), 0.38 \mathrm{kcal} \mathrm{mol}^{-1}$, is $2.2 \mathrm{kcal} \mathrm{mol}^{-1}$, if the two uncertainties are independent. This value was obtained by taking the square root of the sum of the squares of the terms $(4.222)(0.51)$ and $(1)(0.38)$ in which the coefficients of the uncertainties are the numbers of 
moles of products formed in the combustion reaction. The same calorimetric system and procedures for sample preparation were used in determining the heats of formation of $\mathrm{BF}_{3}(\mathrm{~g})$ and $\mathrm{CF}_{4}(\mathrm{~g})$ as have been employed in the present work. Hopefully, because of these features, certain systematic errors that could have occurred in the work on $\mathrm{BF}_{3}$ and $\mathrm{CF}_{4}$ would also occur in the present study, and would tend to cancel out in the calculation of the heat of formation of boron carbide.

Errors incurred in performing the heat measurements such as the errors from calibration or combustion experiments, losses in sample preparation, analysis of the amount of unburned boron carbide and incomplete fuse combustion are adequately covered by using two times the standard deviation of the mean, or $1.0 \mathrm{kcal} \mathrm{mol}^{-1}$.

An overall experimental error is calculated by taking the square root of the sum of the squares of these four errors. We obtain $2.7 \mathrm{kcal} \mathrm{mol}^{-1}$ as the estimated error in the heat of formation of boron carbide.

\subsection{Comparison with Other Work}

The calculation of the heat of formation of boron carbide from the work of Smith, Dworkin, and van Artsdalen [1] can be placed on a more current reference base for comparison with our data by introducing a more appropriate value for the heat of formation of amorphous boric oxide into their data. If we use $\Delta H_{f 298}^{\circ}\left[\mathrm{B}_{2} \mathrm{O}_{3}\right.$ (amorphous) $]=-299.84 \mathrm{kcal}^{-1}$ [28], the value of Smith et al., for $\Delta H_{f 298}^{\circ}\left[\mathrm{B}_{4} \mathrm{C}(\mathrm{c})\right]$ becomes $-9.9 \mathrm{kcal} \mathrm{mol}^{-1}$.

We feel that our measurements on boron carbide are an improvement over the previous work [1] because of the greater completeness of combustion, the greater attention given to the analysis of the sample, and the probable cancellation of certain systematic errors as a result of having the heats of formation of $\mathrm{BF}_{3}$ and $\mathrm{CF}_{4}$ determined in the same calorimetric system. However, inspection of our value and that of Smith, et al. [1] for the heat of formation of boron carbide shows that the difference in these values is somewhat larger than the sum of the reported uncertainties. It is quite possible that this difference is due to the dissimilarity in the stoichiometries of the respective samples.

The heat of formation of boron carbide has been used to calculate the heat of formation of $B(g)$ from measurements of the vaporization of $B_{4} C$, reaction (4), using mass spectrometric and effusion techniques.

$$
1 /{ }_{4} \mathrm{~B}_{4} \mathrm{C}(\mathrm{c})=\mathrm{B}(\mathrm{g})+1 / 4 \mathrm{C}(\mathrm{c})
$$

The direct measurement of the heat of formation of $\mathrm{B}(\mathrm{g})$ was made with these two techniques from the vaporization of elemental boron, reaction (5).

$$
\mathrm{B}(\mathrm{c})=\mathrm{B}(\mathrm{g})
$$

The JANAF Thermochemical Tables [21] summarize the vaporization data that are available from studies on reactions (4) and (5) under the heading: Boron, Monatomic, (Ideal Gas). Close examination of this summary shows a possible systematic error in the value calculated for $\Delta H_{f 298}[\mathrm{~B}(\mathrm{~g})]$ of about $5 \mathrm{kcal} \mathrm{mol}^{-1} \mathrm{de}$ pending upon whether mass spectrometric or effusion techniques were used. A possible solution to this disparity is a larger negative value for $\Delta H_{f 298}^{\circ}\left[\mathrm{B}_{4} \mathrm{C}(\mathrm{c})\right]$. However, the application of either our value or that of Smith, Dworkin, and van Artsdalen for $\Delta H_{f 298}^{\circ}\left[\mathrm{B}_{4} \mathrm{C}(\mathrm{c})\right]$ to the available vaporization data on $\mathrm{B}_{4} \mathrm{C}$ changes $\Delta H_{f 298}^{\circ}[\mathrm{B}(\mathrm{g})]$ by less than $2 \mathrm{kcal} \mathrm{mol}^{-1}$. It appears, therefore, that other areas ought to be explored in order to resolve the apparent discordance in the heat of formation of $B(\mathrm{~g})$.

\section{References}

[1] D. Smith, A. S. Dworkin, and E. R. van Artsdalen, J. Am. Chem. Soc. 77, 2654-6 (1955).

[2] E. J. Prosen, W. H. Johnson, and F. Y. Pergiel, J. Res. NBS 62, 43-7 (1959) RP2927.

[3] Dow Chemical Company, JANAF Thermochemical Tables Addendum. PB 168370-1 (Clearinghouse for Federal Scientific and Technical Information, Springfield, Virginia, 1966).

[4] G. V. Samsonov, Zh. Prikl. Khim. 28, 1018-21 (1955).

[5] L. Ya. Markovskii, D. L. Orshanskii, and V. P. Pryanishnikov, Khim. Elektrotermiya, Goskhimizdat, 207-215 (1952).

[6] A. V. Tikhonov, Tr. Tsentral. Nauchno-Issled. Lab. Abraz. i Shlifov. No. 6 (1937)

[7] I. S. Gaev, (a) Zh. Neorgan. Khim. 1, 193-211 (1956); (b) Metalograficheskii altas zheleznykh splavov (Metallurgizdat, Leningrad-Moskva, 1951).

[8] P. A. G. O'Hare, J. L. Settle, and W. N. Hubbard, Trans. Faraday Soc. 62, 558-565 (1966).

[9] E. S. Domalski and G. T. Armstrong, J. Res. NBS $71 \mathbf{A}$ (Phys. and Chem.), No. 4, 307-315 (1967).

[10] H. K. Clark and J. L. Hoard, J. Am. Chem. Soc. 65, 2115-9 (1943).

[11] R. D. Allen, J. Am. Chem. Soc. 75, 3582-3 (1953).

[12] E. S. Domalski and G. T. Armstrong, J. Res. NBS 71 A (Phys. and Chem.), No. 2, 105-118 (1967).

[13] G. T. Armstrong and R. S. Jessup, J. Res. NBS 64A (Phys. and Chem.), No. 1, 49-59 (1960).

[14] E. S. Domalski and G. T. Armstrong, J. Res. NBS 71A (Phys. and Chem.), No. 3, 195-202 (1967).

[15] W. Primack and P. Day, Anal. Chem. 26, 1515-17 (1954).

[16] E. S. Domalski and G. T. Armstrong, J. Res. NBS 69A (Phys. and Chem.), No. 2, 137-147 (1965).

[17] C. H. Shomate, Computer Calculations of Combustion Bomb Calorimetric Data, Technical Progress Report 327, NOTS TP3288, U.S. Naval Ordnance Test Station, China Lake, California, August 1963.

[18] O. E. Myers and A. P. Brady, J. Phys. Chem. 64, 591-4 (1960).

[19] W. D. Good, D. W. Scott, and G. Waddington, J. Phys. Chem. 60, 1080-9 (1956).

[20] W. H. Evans, J. Hilsenrath, and H. W. Woolley, NBS, private communication, July 1, 1960.

[21] Dow Chemical Company, JANAF Thermochemical Tables, PB 168370 (Clearinghouse for Federal Scientific and Technical Information, Springfield, Virginia, 1965).

[22] W. H. Evans, NBS, private communication, January 1, 1961.

[23] W. N. Hubbard, Fluorine Bomb Calorimetry, ch. 6, Experimental Thermochemistry, Vol. II, H. A. Skinner, editor (Interscience Publishers, Inc., New York, 1962).

[24] J. O. Hirschfelder, C. F. Curtiss, and R. B. Bird, Molecular Theory of Gases and Liquids (John Wiley and Sons, Inc., New York, copyright 1954, Second Printing, 1964).

[25] D. White, J. H. Hu, and H. L. Johnston, J. Chem. Phys. 24, 1149-52 (1953).

[26] D. R. Douslin, paper No. 11, pp. 135-46, PVT Relations and Intermolecular Potentials for Methane and Carbon Tetrafluoride, in Progress in International Research on Thermodynamic and Transport Properties, J. F. Masi and D. H. Tsai, editors (Academic Press, New York, 1962).

[27] G. L. Brooks and C. J. G. Raw, Trans. Faraday Soc. 54, 972-4 (1958). 
[28] D. D. Wagman, W. H. Evans, I. Halow, V. B. Parker, S. M. Bailey, and R. H. Schumm, NBS Tech. Note 270-3 (Jan. 1968).

[29] F. D. Kossini, D. D. Wagman, W. H. Evans, S. Levine, and I. Jaffe, Selected Values of Chemical Thermodynamic Properties, NBS Circular 500 (U.S. Government Printing Office, Washington, D.C., 1952).

[30] L. Brewer, L. A. Bromley, P. W. Gilles, and N. Lofgren, The Thermodynamic Properties of the Halides, paper 6, Chemistry and Metallurgy of Miscellaneous Materials: Thermodynamics, L. L. Quill, editor (McGraw-Hill Book Co., Inc., New York, 1950).
[31] E. Rudzitis, H. M. Feder, and W. N. Hubbard, J. Phys. Chem. 68, 2978-81 (1964).

[32] S. S. Wise, J. L. Margrave, H. M. Feder, and W. N. Hubbard, J. Phys. Chem. 67, 815-21 (1963).

[33] E. Greenberg, J. L. Settle, H. M. Feder, and W. N. Hubbard, J. Phys. Chem. 65, 1168-72 (1961).

[34] E. Greenberg, J. L. Settle, and W. N. Hubbard, J. Phys. Chem. 66, 1345-8 (1962).

[35] A. E. Cameron and E. Wichers, J. Am. Chem. Soc. 84, 4175-97 (1962).

(Paper 72A2-488) 